\title{
Solar eclipse effects of 22 July 2009 on Sporadic-E
}

\author{
G. Chen, Z. Zhao, C. Zhou, G. Yang, and Y. Zhang
}

School of Electronic Information, Wuhan University, Wuhan, Hubei, China

Received: 8 September 2009 - Revised: 8 January 2010 - Accepted: 25 January 2010 - Published: 1 February 2010

\begin{abstract}
The total solar eclipse of 22 July 2009, was visible from some regions of China and the intense sporadic-E (Es) that broke out during the solar eclipse period over the eastern China provided a unique chance to study solar eclipse effects on the Es-layer. The ground based high-frequency (HF) vertical-incidence and oblique-incidence backscatter radio systems in Wuhan and an HF oblique receivers located in Suzhou were operated to detect the Es-layer. The vertical, oblique and backscatter ionograms of 22 and 23 July were recorded, processed and analyzed. The analyzing results show that the critical frequency of Es, the hop number and power of the rays transmitted from Wuhan to Suzhou as well as the Doppler frequency shift of the one-hop obliqueincidence waves reflected by the Es-layer all increased during the solar eclipse period. These variations are displayed in the paper and explained to be induced by the wind-field, which is produced by the powerful meridional air flows from the sunshine region to the moon's shadow.
\end{abstract}

Keywords. Ionosphere (Mid-latitude ionosphere; Solar radiation and cosmic ray effects)

\section{Introduction}

A solar eclipse provides us with a rare opportunity to study the ionospheric effects associated with an accurately estimated variation of solar radiation during the eclipse period. Wuhan city on the path of the total solar eclipse of 22 July 2009 is one of the perfect locations for observation and it is very convenient for the Ionospheric Laboratory of Wuhan University to carry out the observing experiment. The vertical-incidence ionosonde (Abraham et al., 1998; Altadill et al., 2001; Bamford, 2001; Jakowski et al., 2008), the oblique-incidence ionospheric sounding systems (Boitman et al., 1999) and the oblique-incidence backscatter ionospheric

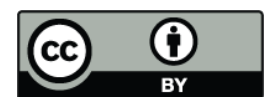

Correspondence to: G. Chen (g.chen@whu.edu.cn) sounding system (Davis et al., 1964) were all applied to observe the ionospheric behavior. The continuous appearance of the intense Es-layer during the eclipse and post-eclipse days provided a unique chance to study solar eclipse effects on Es and discover the relationship between solar radiation and features of Es (Whitehead, 1989).

In this paper, we describe the observations of Es behavior during the total solar eclipse that occurred over eastern China on 22 July 2009. The variation of Es was observed by three kinds of HF ground based radio systems and useful parameters were obtained from the recorded vertical, oblique and backscatter ionograms. The critical frequencies of Es recorded by the ionosonde and the delay, echo power and Doppler frequency shift (DFS) recorded by the Suzhou oblique receiver in the eclipse and post-eclipse day are displayed and analyzed.

\section{Observations}

On Wednesday, 22 July 2009, a total eclipse of the Sun was visible within a narrow corridor that traverses half of Earth. The path of the Moon's umbral shadow started in India and crossed through Nepal, Bangladesh, Bhutan, Myanmar and China. The solar eclipse in eastern China started at about 01:30 UT and it lasted for two and half hours. Ionospheric detection experiments were carried out during this time and also on the post eclipse day.. The vertical-incidence ionosonde and the Wuhan ionospheric oblique backscatter sounding system (WIOBSS) were placed in Wuhan (Chen et al., 2007) and one HF digital receiver was carried to Suzhou to receive the transforming signals from the WIOBSS for oblique-incidence ionograms (Chen et al., 2009). The latitude and longitude of Wuhan and Suzhou as well as the eclipse beginning, totality and end time of the two cities are shown in Table 1. The referred total eclipse timings are at the ground level.

The ionosonde records the frequency, height, amplitude, phase, Doppler shift and spread of reflected signals received from the ionosphere to produce the ionograms. In the

Published by Copernicus Publications on behalf of the European Geosciences Union. 
Table 1. Location and solar eclipse time of Wuhan and Suzhou.

\begin{tabular}{ccccc}
\hline City & Location & $\begin{array}{c}\text { Eclipse } \\
\text { begin }\end{array}$ & $\begin{array}{c}\text { Eclipse } \\
\text { totality }\end{array}$ & $\begin{array}{c}\text { Eclipse } \\
\text { end }\end{array}$ \\
\hline Wuhan & $30^{\circ} 32^{\prime} \mathrm{N}, 114^{\circ} 21^{\prime} \mathrm{E}$ & $00: 14$ & $01: 26$ & $02: 46$ \\
Suzhou & $31^{\circ} 04^{\prime} \mathrm{N}, 120^{\circ} 25^{\prime} \mathrm{E}$ & $00: 22$ & $01: 37$ & $02: 59$ \\
\hline
\end{tabular}

solar eclipse period, the vertical-incidence ionograms were recorded between 3 and $18 \mathrm{MHz}$ with $100 \mathrm{kHz}$ step every $5 \mathrm{~min}$. The WIOBSS used the log-periodic antenna pointed due east and was conducted at the frequencies of $6.6,8.2$ and $10.6 \mathrm{MHz}$. The oblique incident detection started at 00:00 UT and the channel scattering functions of the three operating frequencies were recorded every one minute (Kay and Doyle, 2003). The Doppler range determined by the applied waveform was $[-4.7 \mathrm{~Hz},+4.7 \mathrm{~Hz}]$ and the Doppler resolution was $0.0735 \mathrm{~Hz}$. An HF digital receiver was located in Suzhou to receive the transmitted signals from Wuhan at the three frequencies. Suzhou in the east of Wuhan is also an ideal eclipse observing location in China and the ionosphere, which reflected the rays from Wuhan to Suzhou, is in the total solar eclipse region.

\section{Results and discussions}

In observing Es on a larger time scale, it is well documented that Es occurs most often in the summer of mid-latitude (Smith, 1957; Pocock and Dyer, 1992). The eclipse day of 2009 and the day before and after were also not immune to it. In the morning of 22 and 23 July, intense Es broke out. The elevated and widespread ionization shadowed the whole sky and no echo from the F-layer could be received by HF ground based systems. Although the F-layer hadn't been observed, the solar eclipse effects on the shadowing Es-layer could be studied.

The Es consistently occurs around $100 \mathrm{~km}$ and the ordinary critical frequency of Es ( $f_{0}$ Es) is unpredictable. Sometimes the value of $f_{0}$ Es is many times higher than its mean value (Chavdarov, 1968). For the shadowing Es-layer that occurred on 22 and 23 July, the blanketing frequency $f_{b}$ Es is approximately equal to the critical frequency $f_{0}$ Es (Piggott and Rawer, 1961; Reddy and Rao, 1968). As shown in Fig. 1, the $f_{0}$ Es of 23 July is a periodic curve with an amplitude between 6 and $15 \mathrm{MHz}$ and a period of about $80 \mathrm{~min}$. The $f_{0}$ Es on the eclipse day (22 July) had a similar periodic curve before the eclipse totality time (the maximum phase) and then suddenly increased from 9 to $14.1 \mathrm{MHz}$ at 01:43 UT. The high $f_{0}$ Es value was maintained, accompanied by two peaks until and after the eclipse ended. The sudden increase of $f_{0}$ Es in the solar eclipse period was also observed over Haringhata in 1955 (Datta, 1972, 1973). It is worth noting

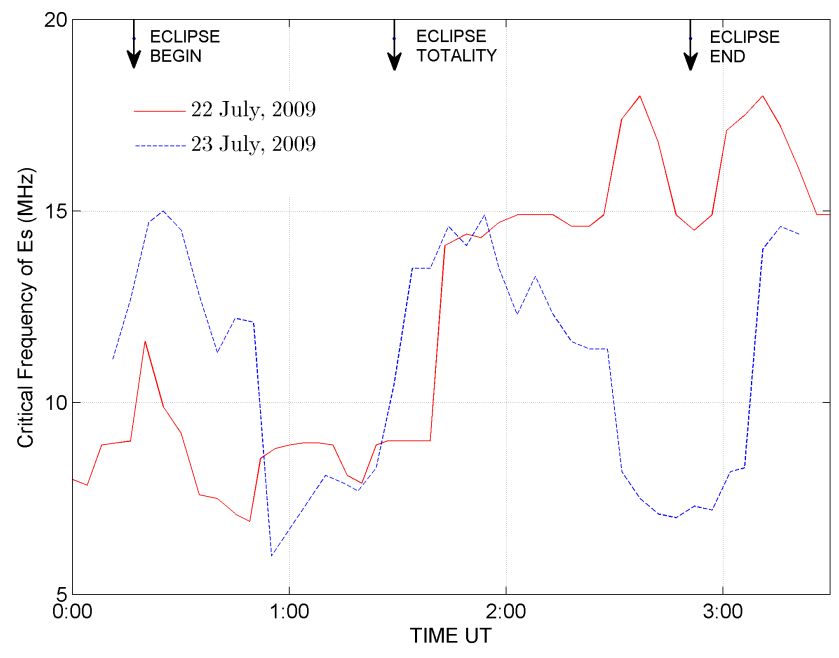

Fig. 1. Variation of $f_{0}$ Es during the total solar eclipse day of 22 July 2009 and the post-eclipse day of 23 July 2009 over Wuhan.

that when the solar radiation decreased during totality, the maximum electron concentration of Es did not fall but rose.

Figure 2 displays two delay-time oblique ionograms recorded by the Suzhou HF receiver at $6.6 \mathrm{MHz}$ on 22 and 23 July 2009. By the $2.08 \mathrm{~ms}$ delay of the one-hop radio wave and the $582.68 \mathrm{~km}$ distance between Wuhan and Suzhou, the altitude of the reflecting layer is estimated as about $112.9 \mathrm{~km}$ and therefore the reflections must be due to an Es-layer.. Compared with Fig. 2b, the signal power and hop number in Fig. 2a began to increase at 00:48 UT after the first contact. The power reached its maximum value at 01:31 UT, the time between the eclipse totality time of Wuhan and Suzhou. Then the wave power started to drop off and the third- and fourth-hop radio waves were weakened and disappeared gradually. The appearance of the third- and fourth-hop radio waves during the solar eclipse period in the oblique ionogram shows that the rays of less incident angle were reflected to the ground but not penetrated, implying the increase of the electron concentration of Es.

To study the transient phenomena on short time scales, the Doppler measurements were also used at frequencies of 6.6, 8.2 and $10.6 \mathrm{MHz}$. The radio wave was transmitted to the east from Wuhan and received in Suzhou. The Doppler values were drawn out from the one-hop wave reflected by Es. The temporal variation of DFS recorded on 22 and 23 July 2009 is given in Figs. 3 and 4, respectively. Compared with the DFS recorded on 23 July, the DFS recorded on the eclipse day has much larger fluctuation scale between $[-0.5 \mathrm{~Hz}$, $+0.5 \mathrm{~Hz}]$. The large DFS fluctuation, as shown in Fig. $3 \mathrm{~b}$ at $8.2 \mathrm{MHz}$, appeared after the first contact. The large-scale DFS fluctuation was continuously produced at the three operating frequencies after the eclipse totality time and before the eclipse end time. After the eclipse ended, some DFS fluctuation still existed. The Doppler variation was also observed 


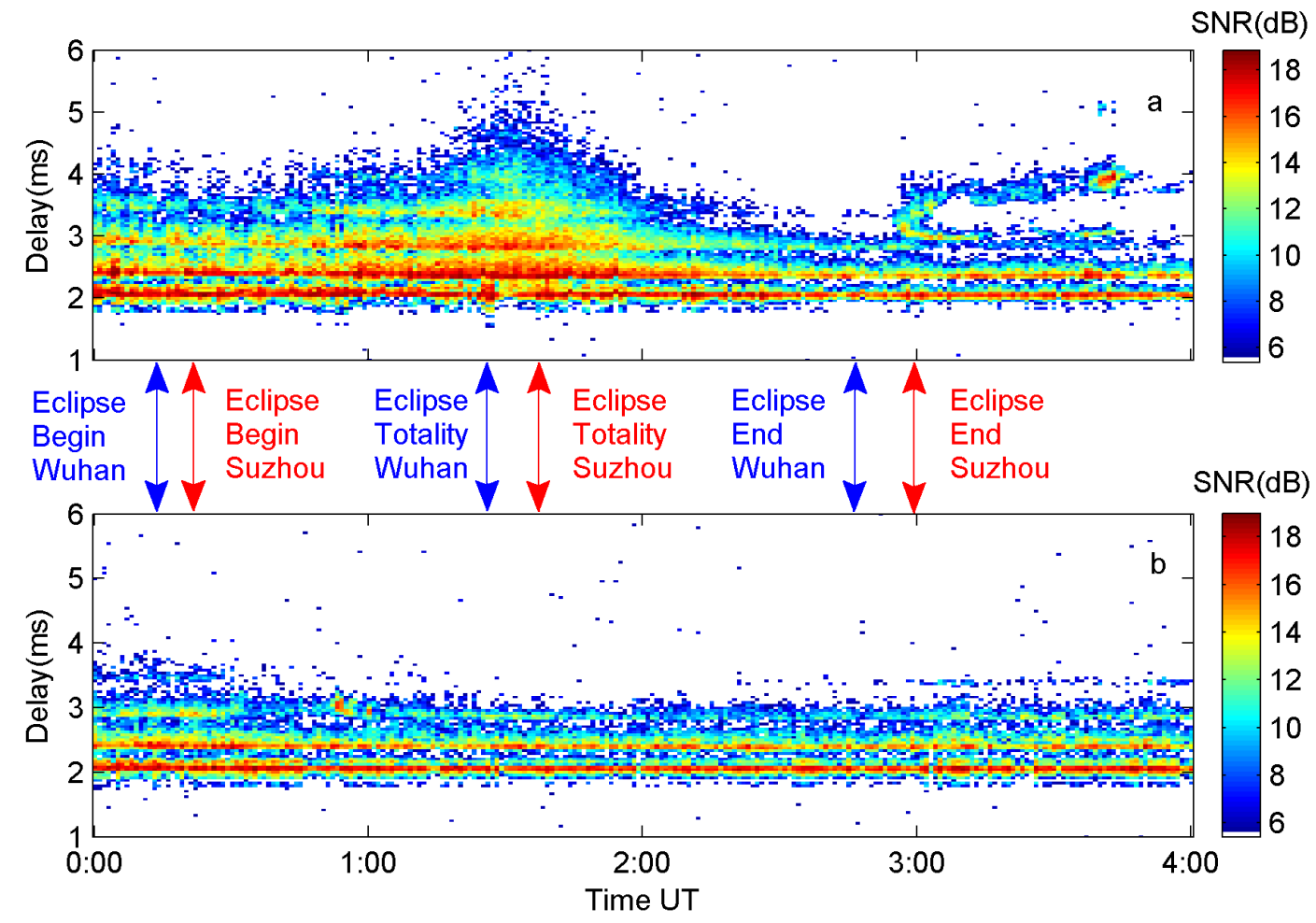

Fig. 2. The delay-time oblique ionograms of Wuhan-to-Suzhou line. Panels (a) and (b) are the echoes recoded at $6.6 \mathrm{MHz}$ operating frequency in the morning of 22 and 23 July, respectively. The solar eclipse time of Wuhan and Suzhou is marked on the figure.

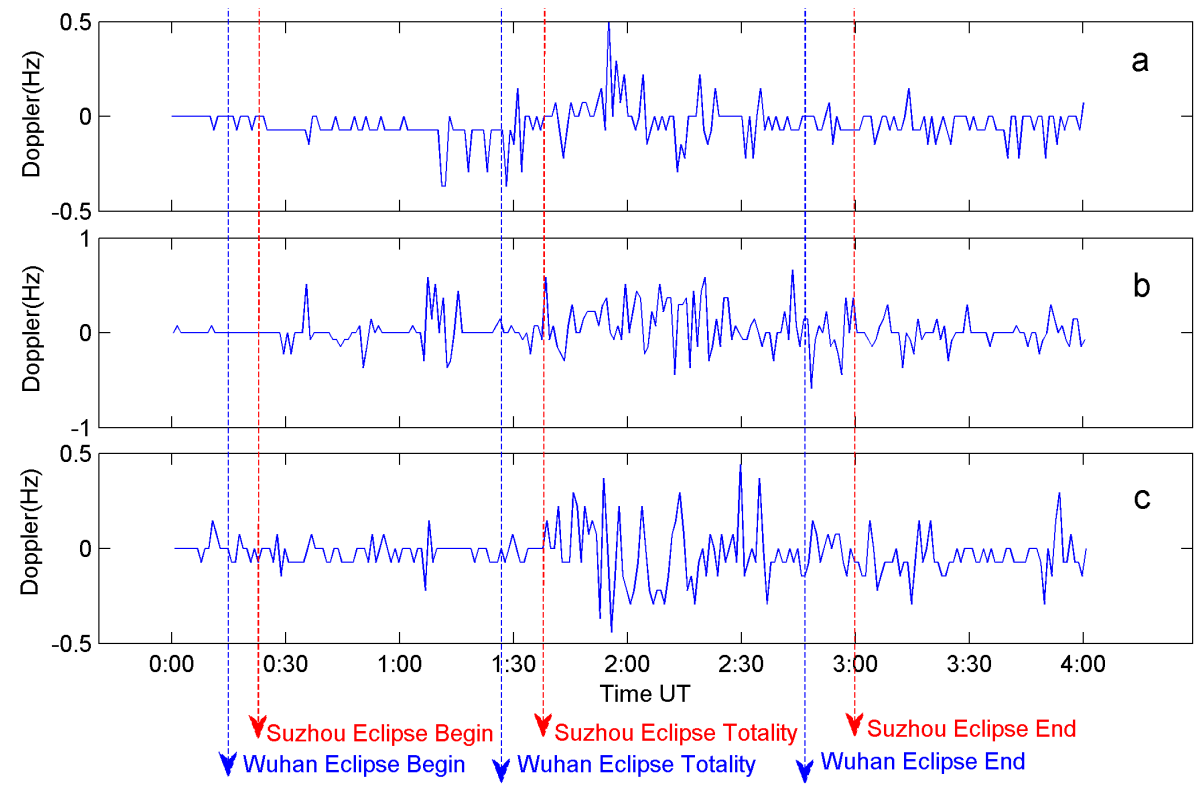

Fig. 3. The temporal variation of DFS of one-hop wave reflected by Es recorded by the Suzhou receiver at (a) 6.6 , (b) 8.2 and (c) $10.6 \mathrm{MHz}$ on 22 July 2009. The solar eclipse beginning, totality and end time of Wuhan and Suzhou is marked by blue and red lines, respectively.

during the solar eclipse of 3 October 2005 (Jakowski et al., 2005).
The large DFS illustrates the rapid movement of the ionized clouds in the Es-layer, which perhaps was induced by the local cooling of the atmosphere by the Moon's shadow 


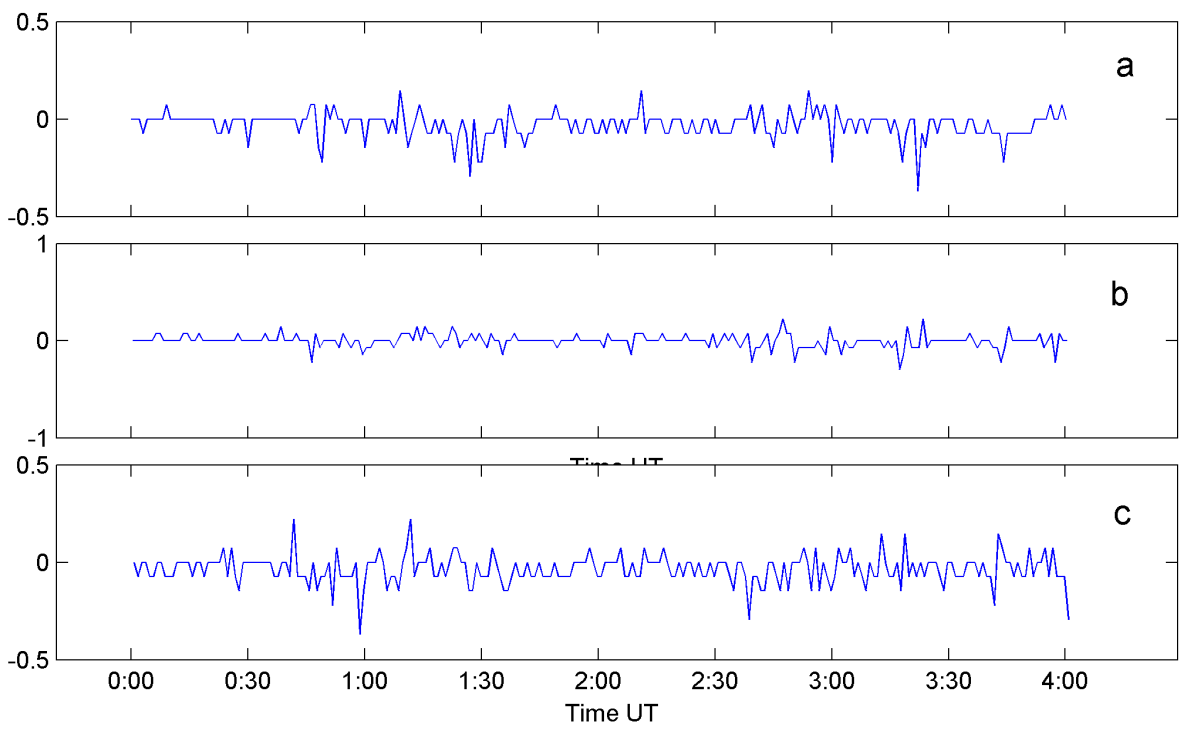

Fig. 4. The temporal variation of DFS of one-hop wave reflected by Es recorded by the Suzhou receiver at (a) 6.6 , (b) 8.2 and (c) $10.6 \mathrm{MHz}$ on 23 July 2009.

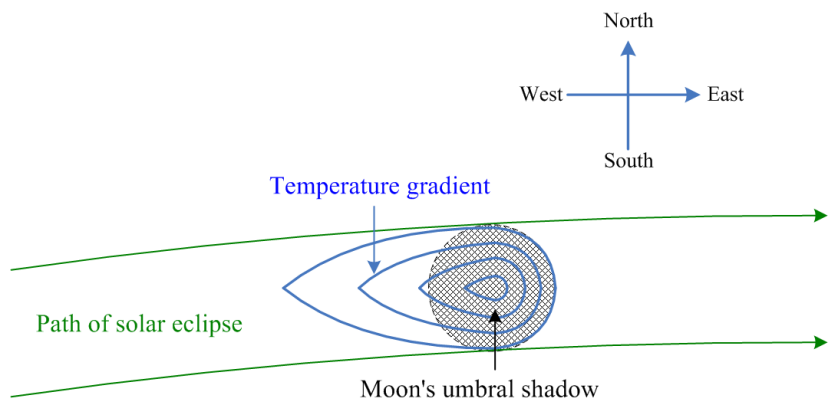

Fig. 5. The schematic diagram of the proposed mechanism for the Es enhancement.

(Boitman et al., 1999). When the 243.3km-width Moon's shadow moved from west to east at supersonic speed, the instant cooling induced the large temperature gradient on the eclipse path. As shown in Fig. 5, on the altitude of Es-layer the advancing edge of the shadow continuously moved ahead to cool off the atmosphere before it began to flow; the cooled atmosphere behind the shadow had small temperature gradient. Therefore, the wind field in the zonal direction (east or west) was weak. There was large temperature difference on the northern and southern limit of the shadow and the powerful air flowed into the shadowing region from north and south respectively to form the appropriate meridional component of the wind field, which was much more powerful than the zonal component. The meridional airflow accelerated the ionized clouds in the Es-layer and encountered in the shadow center to form the wind shear. It is the wind shear inducing intensification in the Es-layer (Whitehead, 1961, 1989; Mathews, 1998) and increase of $f_{0}$ Es during the solar eclipse period.

\section{Conclusion}

Due to the unique opportunity to observe the behavior of the ionosphere in the total solar eclipse day of 22 July 2009, we applied all the radio systems we have and attempted to discover the relationship between solar radiation and features of Es by the recorded ionograms and the integrated analysis. The solar eclipse effects on Es are very obvious. The $f_{0}$ Es obtained by the ionosonde in Wuhan, the hop number and power of the oblique-incidence rays from Wuhan to Suzhou and the wave DFS value of Es all increased during the total solar eclipse period. The cooling effect of the moon's shadow is believed to induce the powerful meridional airflow in the atmosphere, which accelerated the ionized clouds in the Eslayer and formed the wind shear to raise the observed DFS and $f_{0}$ Es values, respectively.

To certify that the $f_{0}$ Es enhancement was indeed associated with the eclipse, and had not occurred by chance, more observed data from different places on the eclipse path are needed. If a digisonde operated in the drift mode on the northern or southern limit of the total solar eclipse path, the horizontal drift of the ionized clouds in Es-layer could be observed. However, it is a small probability event and perhaps the next Es-layer on the eclipse path will appear several decades later. It is necessary to build a temperature and wind field model of conditions during the solar eclipse to research the dominated wind component at the Es-layer altitude.

Acknowledgements. We are indebted to Ming Yao, Shipeng Li, Xinmiao Zhang, Jun Song, Suo Huang, Ning Li and Zuowei He for help in organizing the experiment and grateful to Chris Davis for a critical reading of the manuscript and for his helpful comments. This research is supported by the National Natural Science Foundation of China (40804042). 
Topical Editor K. Kauristie thanks C. J. Davis and another anonymous referee for their help in evaluating this paper.

\section{References}

Abraham, S., Dhaka, S. K., Nath, N., and Baluja, K. L.: Ionospheric absorption on October 24, 1995 solar eclipse, Geophys. Res. Lett., 25(15), 2945-2947, 1998.

Altadill, D., Solé, J. G., and Apostolov, E. M.: Vertical structure of a gravity wave like oscillation in the ionosphere generated by the solar eclipse of August 11, 1999, J. Geophys. Res., 106(A10), 21419-21428, 2001.

Bamford, R. A.: The effect of the 1999 total solar eclipse on the ionosphere, Phys. Chem. Earth, 26(5), 373-377, 2001.

Boitman, O. N., Kalikhman, A. D., and Tashchilin, A. V.: The midlatitude ionosphere during the total solar eclipse of March 9, 1997, J. Geophys. Res., 104(A12), 28197-28206, 1999.

Chavdarov, S. S., Chernysheva, S. P., and Svechnikov, A. M.: Influence of radio wave absorption in the ionosphere on the variation of sporadic E layer parameters, Geomagn. Aeron, 8, 294-298, 1968.

Chen, G., Zhao, Z., and Zhang, Y.: Ionospheric Doppler and echo phase measured by the Wuhan Ionospheric Oblique Backscattering Sounding System, Radio Sci., 42, RS4007, doi:10.1029/2006RS003565, 2007.

Chen, G., Zhao, Z., Zhu, G., and Shi, S.: The Wuhan Ionospheric Sounding Systems, IEEE Geosci. Remote Sens. Lett., 6(4), 748$751,2009$.
Datta, R. N.: Solar-Eclipse Effect on Sporadic-E Ionization, J. Geophys. Res., 77(1), 260-262, 1972.

Datta, R. N.: Solar Eclipse Effect on Sporadic E Ionization, 2, J. Geophys. Res., 78(1), 320-322, 1973.

Davis, J. R., Headrick, W. C., and Ahearn, J. L.: A HF Backscatter Study of Solar Eclipse Effects upon the Ionosphere, J. Geophys. Res., 69(1), 190-193, 1964.

Jakowski, N., Stankov, S. M., Wilken, V., Borries, C., Altadill, D., Chumc, J., Buresova, D., Boska, J., Sauli, P., Hruska, F., and Cander, Lj. R.: Ionospheric behavior over Europe during the solar eclipse of 3 October 2005, J. Atmos. Sol. Terr. Phys., 70(6), 836-853, 2008.

Kay, S. M. and Doyle, S. B.: Rapid estimation of the range-Doppler scattering function, IEEE Trans. Signal Process., 51(1), 255268, 2003.

Mathews, J. D.: Sporadic E: current views and recent progress, J. Atmos. Solar-Terr. Phys., 60(4), 413-435, 1998.

Piggott, W. R. and Rawer, K.: URSI handbook of ionogram interpretation and reduction, Elsevier, 1961.

Pocock, E. and Dyer, P. J.: Eleven Years of Sporadic E, QST, 23-28, 1992.

Reddy, C. A. and Rao, M. Mukunda: On the Physical Significance of the Es Parameters fbEs, fEs, and foEs, J. Geophys. Res., 73(1), 215-224, 1968.

Smith, E. K.: Worldwide Occurrence of Sporadic E, National Bureau of Standards Circular, 582, 1957.

Whitehead, J. D.: The formation of the sporadic-E layer in the temperate zones, J. Atmos. Terr. Phys., 20(1), 49-58, 1961.

Whitehead, J. D.: Recent work on mid-latitude and equatorial sporadic-E, J. Atmos. Terr. Phys., 51(5), 401-424, 1989. 